\title{
The Effect of Scaffolding Technique in Journal Writing among the Second Language Learners
}

\author{
Veeramuthu A/L Veerappan \\ Multimedia University, Malaysia \\ Email: veeramuthu@mmu.edu.my
}

\author{
Wei Hui Suan \\ Centre for Foundation Studies and Extension Education, Multimedia University, Cyberjaya, Malaysia
}

Tajularipin Sulaiman

Faculty of Educational Studies, University Putra, Malaysia

\begin{abstract}
It was noted that one of the most distressing challenges faced by the L2 college students was the poor presentation of their journal writing skills. The researcher noticed a prevailing pattern in their journal writing, where most of them were unable to construct proper sentences, making too many grammatical errors and also lacking in vocabulary. These factors have eventually restricted them from expressing their ideas clearly and effectively in their journal writing. Therefore, this study is primarily designed to look at how second language learners have acquired the use of English language through journal writing and how they have improved within a short time frame. The researcher scaffold a number of 3 undergraduate university college students by using several interactive writing techniques and instructions in writing a journal which showed their progress, daily activities and new experiences. The writing errors from the samples of written journals during week 1 were as it was written before and during the scaffolding period. Data were collected and the results of the progression were obtained based on the observation and comparison of written journals on week 1 and 5. The scaffolding technique presented in this study has helped remedy the challenges faced by the target students by further developing their effectiveness in journal writing.
\end{abstract}

Index Terms—scaffolding, second language learners, journal writing skills, interactive writing skills, English language learner

\section{INTRODUCTION}

Effective journal writing skills are important to the personal and professional development of second language (L2) college students. These skills are necessary for them to recognize their journal writing strengths and venture further into the areas for improvement. However, it was noted that one of the most distressing challenges faced by the L2 college students was the poor presentation of their journal writing skills. We noticed a prevailing pattern in their journal writing, where most of them were unable to construct proper sentences, making too many grammatical errors and also lacking in vocabulary. These factors have eventually restricted them from expressing their ideas clearly and effectively in their journal writing.

In the classroom, scaffolding is a process by which a teacher provides students with a temporary framework for learning. When scaffolding is done correctly, students are encouraged to develop their own creativity, motivation, and resourcefulness. As students gather knowledge and increase their skills on their own, fundamentals of the framework are dismantled. At the completion of the lesson, the scaffolding is removed altogether and students no longer need it (Lawson, 2002). Walqui (2002) maintained that scaffolding can be thought of as three related pedagogical scales:

1. Providing a support structure to the students to enable certain activities and skills to develop.

2. Carrying out particular activities in class.

3. Providing assistance in moment-to- moment interaction.

Scaffolding is an instructional technique whereby the teacher models the desired learning strategy or task and then gradually shifts responsibility to the students. This type of interaction is consistent with Vygotsky's (1978) belief that learning is a social process and not an individual one, and it occurs when students interact with their teacher and with one another in the classroom.

Although Vygotsky (1978) did not use the term scaffolding, it does have a theoretical basis in his description of the Zone of Proximal Development (ZPD). He defined the ZPD as the distance between the actual development level of the learner, as determined by independent problem solving, and the level of potential development, as determined through problem solving under teacher guidance and interaction and collaboration with more capable student peers (Doolittle, 1997). The ZPD is represented in a model with four stages (Tharp \& Gallimore, 1988). This model illustrates the scaffolding process and it represents the relationship between teacher and student interaction in group settings. ZPD 
stages defined by Herber and Herber (1993) in stage 1 of the ZPD or scaffolding, there is frequent teacher and student interaction because the teacher needs to provide the student with the literal facts, details, key names, and dates related to the concepts or ideas being taught. In stage 2, students work together in small groups, and the teacher provides them with activities that encourage interpretation through metacognition or the knowledge of when and how to use certain strategies to solve writing related problems and teacher's guided practice. In stages 3 and 4 , the students continue to work together and independently while applying the information that they have learned to new ideas and concepts.

Scaffolding techniques have been used in many studies and have shown positive results. According to Mitchell and Myles (2004), the domain where learning can most productively take place is christened the Zone of Proximal Development (ZPD), that is, the domain of knowledge or skill where the learner is not yet capable of independent functioning, but can achieve the desired outcome given relevant scaffolded help from the teachers or mentors. Thus the learners current stage in learning could be develop further by providing proper guidance through scaffolding which would guide the learners to develop to a stage where the learners build the necessary knowledge independently.

One of many examples of studies on scaffolding is the study by Belland, Glazewski and Richardson (2007) where problem-based learning was used as an approach with middle school students in order to help to build their critical reasoning skills. A small group of students were engage in an authentic, ill-structured problem. They have to understand the problem, develop a possible solution, provide evidence to support and present it. Various scaffolding methods were used to help these students. The study concluded that the output intent of scaffolding is to serve as a temporary support until students are able to accomplish scaffolding tasks by themselves. Scaffolding at the beginning stage was through teachers, peers or teaching materials where the students develop from a dependent to an independent stage in acquiring the knowledge.

Next, Communication Skills Development (CSD) system was used in a study by Planas and Nelson (2008) in developing the communication skills of the students. This system integrated self-directed learning activities, feedback and scaffolding strategies where it was shown to be effective in helping students recognize their strengths, areas in need of improvement, as well as implement and evaluate strategies to compare their communication skills. Over time, the amount of support, primarily peer feedback and laboratory instructor guidance, lessened as their communication skills developed. This pattern of participating at an ever-increasing level of competence while at the same time gradually withdrawing support as the learning process unfolds was an application of scaffolding to the CSD system. The outcome of the study showed that the scaffolding technique proof to be very successful. Here, a different technique was used to scaffold the students in order to develop their communication skills. As mentioned earlier, scaffolding was used in the learning process which was gradually reduced and at the end students were able to develop their communication skills.

In another study of grade four struggling readers and writers, Bryan and Christianson (2008) used scaffolding to develop their writing skills. They helped the students with a scaffolded writing experience through the notion of classroom community. Their study suggests that the scaffolding is entirely consistent with the notion of community where individual collaborate and assist one another. The scaffolding here is implemented through peer collaboration where the students help each other in developing their writing abilities and move to a stage of autonomous writers. The notion of classroom community is where the students in the class work as a community in order to help each other. The study used a poem as a based to scaffold the students in writing. The end result was actually very successful especially the scaffolding technique in the learning process. This is another scaffolding technique in developing students to become autonomous learners.

This scaffolding technique is supported by the findings by Vacca (2008) in his research. His research used scaffolding techniques to teach a social studies lesson about Buddha to sixth graders. He suggests teachers using scaffolding as an instructional technique to model the desired learning strategies or tasks for the students throughout the lesson. They should also teach the students to comprehend the relevant information in levels or stages of comprehension that will then gradually shift responsibility of learning about the concept from the teachers to the students. His suggestion shows scaffolding does help the students become autonomous learners. His instruction starts from high level of teacher interaction with students in guiding reading skills with students and leaving the students to participate in small-group interaction. This clearly shows the core idea of scaffolding as seen in other studies above as to gradually shift the learning process from teacher centered learning to more autonomous student centered learning.

The studies mentioned above are examples of scaffolding techniques used in the learning process in developing communication skills, reading and comprehension, and writing. The studies above also show that scaffolding can be used in developing many learning processes and language skills. The major concern would be the language development process through scaffolding. The process begins with the teacher or controlled learning environment controlling the learning process. Then it goes on to the next stage where the teacher only guides or provides partial guidance to the students or by gradually encouraging peer collaboration. Later the learning process is handed over to the students where they have to develop the necessary skills themselves in the specific area. This is where the learning takes place through discovery resulting from the investigation made by the students and now the learners become autonomous learners. The autonomous learners are the ideal aim of scaffolding.

\section{OBJECTIVES}

The objectives of this study are to: 
a) Evaluate the effectiveness of scaffolding strategy in journal writing amongst the L2 undergraduate university college students.

b) Analyze the progress of the L2 university college students in using accurate grammar through the application of scaffolding strategy when writing journals.

\section{RESEARCH QUESTIONS}

a. Is there a significant effect in the use of scaffolding to improve the journal writing skills among university college students?

b. How may the notions of scaffolding contribute to the development of journal writing amongst the L2 university college students?

c. To what extend the effect of scaffolding technique have on the ability of the L2 university college students' grammar accuracy when writing journals?

\section{Methodology}

In this project, the study is primarily designed to look at how second language learner's have acquired the use of English language grammar through journal writing abilities and how they have improved within a short time frame. The researcher scaffold a number of 3 undergraduate university college students by using several interactive writing techniques and instructions in writing a journal which showed their progress, daily activities and new experiences. The writing errors mainly from parts of speech of the samples of written journals during week 1 were as it was written before and during the scaffolding period. Then the researcher compared the sample of written journals of week 1 to week 5. Data were collected and the results of the progression were obtained based on the observation and comparison of written journals on week 1 and 5 .

\section{A. Participants}

3 international undergraduate university college students who are studying intensive English and in their second semester of the business foundation programme in one of the International College in Malaysia were selected as respondents. They are learning to write journals among other academic writing exercises. Prior to starting this semester, these students had completed a previous English writing course which entails a major portion of reading exercises and other approaches to writing. These journals must reflect their academic progress through the weeks of attending lectures and classroom participation. At the same time, students were also encouraged to write about how they developed and improved certain skills, support from classmates and how well they could cope with instructions from the teacher. Throughout the semester, students are required to write a total of seven journals. The first journal was written after completing the first week of classroom learning, activity and participation.

The teacher would provide a format and require the students to hand in their assignments by the end of each week. Sufficient time is given for the student to discuss in class and seek assistance from the teacher. Some of the students submitted drafts for correction and after being reviewed by the teacher they would submit a final copy. The last journal is written and submitted at the end of week 5 .

\section{B. Instrument}

The researcher used five steps to scaffold the students towards completing the journal writing process. The steps are as follows:

1. Checklist for journal writing

2. Draft 1

3. Formulation for journal 1

4. Teacher assistance with correction

5. Sharing 
TABLE 1.

CHECKLIST FOR JOURNAL WRITING

\begin{tabular}{|l|l|l|}
\hline & X & Does the task : \\
\hline 1 & & Require the writer to compose \\
\hline 2 & & Establish clear purpose of communicating ideas \\
\hline 3 & & Motivate the writer to communicate their knowledge \\
\hline 4 & & Reflect kind of writing normally required for academic purposes \\
\hline 5 & & Provide a subject of interest \\
\hline 6 & & Present a topic about yourself \\
\hline 7 & & Use appropriate words \\
\hline 8 & & Present a legible and readable topic \\
\hline 9 & & Present the correct mode of sentence construction \\
\hline 10 & & Give clear and concise approaches for future writing \\
\hline 11 & & Provide evidence for peer support \\
\hline 12 & & Allow writer to express freely \\
\hline & & \\
\hline
\end{tabular}

\section{Evaluation}

In evaluating, the writing task the teacher had considered planning, idea generation, grammar and emphasis on review. When looking closely at the grammar used by the participants, as this was one of the focus of instruction and research, then we viewed this task as purely a grammatical exercise. Two particular areas that we had derived from the scripts were the use of tenses and vocabulary. In most instances, three to five different verbs were used; there were also subject/verb agreement errors and spelling errors by some of the participants. In some cases, there were different verbs used instead of actual words thus showing difference in meaning. The participants had accustomed to using such verbs but not aware of the wrong usage.

In the case of vocabulary, nouns were frequently misspelled, articles often incorrectly placed and little use of adjectives. Many participants had used the same set of words repeatedly in their writing. Despite the use of simple words, when combining to form sentences the meaning that is supposed to be delivered had gone astray. A short clear sentence would have delivered the message with an appropriate choice of vocabulary. Nevertheless, many participants relied on the teacher for support and after correction they were able to present a better piece of paper. It is quite evident that after scaffolding, either grammatically or structurally, the second language learner had acquired the sense of correcting their own work through the editing process or helping in peer edition. In some cases there were clear cases of improvement in the usage of the language by the learner.

\section{RESULTS}

At the end of the fifth week, after the teacher Scaffold the students in journal writing, all of the students were at an improved level where they construct more grammatical sentences, seldom make grey errors, writing a complete and structured sentences, make less frequent repetition of same vocabulary, less errors in punctuation, make little spelling mistakes, able to relate the ideas and form a coherency in writing in comparison to their journal written on week 1.

It is proven to be true that with scaffolding, by the teacher's intervention the students were moved from zone of current development to a zone of proximal development. Beside that the students were able to use the correct time tenses, appropriate use of verbs and adjective and since its journal writing, they were able to reflect and recall the events they experienced earlier and put their progress in written form. After the teacher's intervention to facilitate the students with process writing, now they were able to write effective paragraphs. There are clear thesis statements and topic sentences. Students were able to meet one of the objectives of journal writing that is to provide relevant supporting details as well as interesting introduction and conclusion. It is clear that scaffold is necessary and the students need to be guided step by step to write the journal as to represent their experiences .Most of the students attempted to write on their own, and were independent in learning. They were excited about peer evaluation and discussion during the brainstorming session seems to be very effective and finally towards the end of week 5 they expects very little scaffold by the teacher and were more autonomous in learning.

The table 2 below shows the decrease in the number of mistakes made by the students during pre test (before scaffold) and post test (after scaffold) 


\begin{tabular}{|c|c|c|c|c|c|c|}
\hline \multirow[b]{2}{*}{ Parts Of Speech } & \multicolumn{3}{|c|}{$\begin{array}{l}\text { Number of mistakes } \\
\text { in week } 1\end{array}$} & \multicolumn{3}{|c|}{$\begin{array}{l}\text { Number of mistakes } \\
\text { in week } 5\end{array}$} \\
\hline & Sample 1 & Sample 2 & Sample 3 & Sample 1 & Sample 2 & Sample 3 \\
\hline SVA & 4 & 0 & 2 & 0 & 0 & 2 \\
\hline Noun & 3 & 1 & 0 & 1 & 2 & 0 \\
\hline Pronoun & 9 & 0 & 4 & 1 & 4 & 1 \\
\hline Time tenses & 18 & 5 & 4 & 9 & 2 & 6 \\
\hline Perfect tenses & 6 & 1 & 0 & 3 & 1 & 1 \\
\hline Prepositions & 5 & 0 & 3 & 6 & 4 & 6 \\
\hline Gerund & 1 & 0 & 1 & 0 & 0 & 3 \\
\hline Adjective & 4 & 2 & 2 & 1 & 1 & 3 \\
\hline Verb & 6 & 5 & 4 & 6 & 6 & 1 \\
\hline Articles & 8 & 5 & 2 & 5 & 4 & 3 \\
\hline Vocabulary & 2 & 1 & 8 & 1 & 0 & 2 \\
\hline Spelling & 2 & 1 & 0 & 0 & 0 & 0 \\
\hline Sentence structure & 2 & 1 & 0 & 1 & 0 & 1 \\
\hline Total Mistakes & 68 & 20 & 30 & 32 & 24 & 27 \\
\hline
\end{tabular}

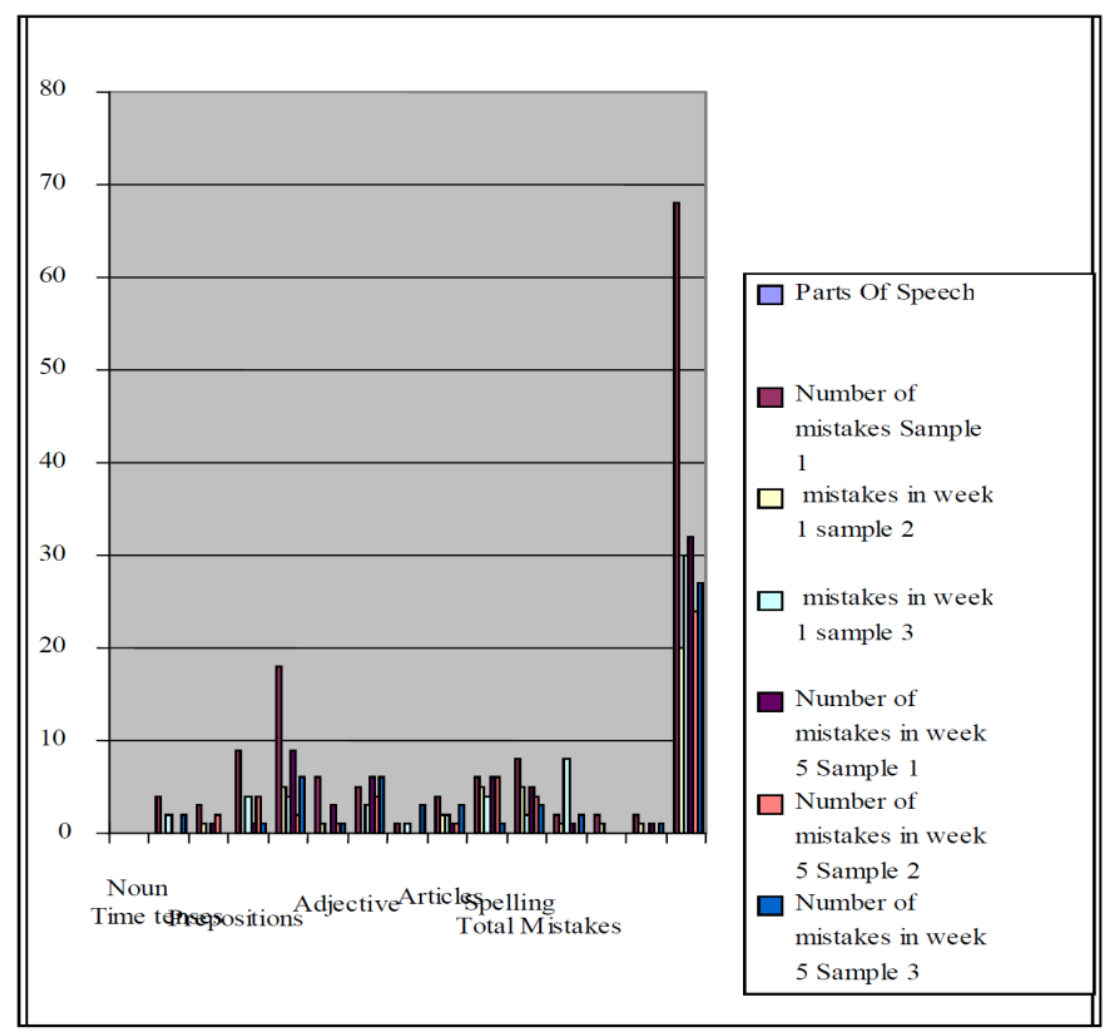

Figure 2 shows the distribution of grammar mistakes made by students in week 1 and 5

\section{DISCUSSION}

For the learners to improve their journal successfully, the teacher helped learners develop strategies they can apply to solve problems they encounter in writing For example, when a student is confronted by an unknown word, rather than telling the word, the teacher scaffold problem solving by prompting the student to use strategies within his or her range, such as using dictionaries to find proper vocabulary and meaning. Eventually, the student's no longer needs the teacher's help and can activate the necessary strategy by themselves.

Based on the results, we cannot generalize that the scaffolding strategy is effective to all the samples as if we see sample 2 made only 20 mistakes in week 1 but the number of mistakes increased to 24 in week 5 . At the same time sample 1 made 68 mistakes in week 1 but significantly showed a decrease in the number of mistakes made in week 5 by only 32 mistakes. Meanwhile, sample 3 shows an improvement in the end of week 5 by making only 27 mistakes compare to the pre test where there was 30 identified mistakes. 
Writing a daily journal when produced by assistance, the students' progress was demonstrated in the use of more advanced appearing forms of writing, increased use of invented spelling, and increased length and quality of the messages. The difference between unassisted writing and Scaffold writing varied between individual students indicating the differences in their zones of proximal development. Scaffold writing followed the predicted path of all scaffolding; it began with assistance by another person, was eventually appropriated or used by the student with little outside support, and later became unnecessary as they reach their zone of proximal development. After the scaffolds were stopped in stages in five weeks, the performance remained at a higher level and there was little regression to earlier level and less mistakes were made compare to week 1.The details of one student's writing deterioration even after the teachers' scaffolding was not present and nor provided in this study as writing a journal is a continuous process and more time is needed to observe the students progress in the following weeks.

\section{CONCLUSION}

In conclusion, we suggest that Scaffold writing provides educators with tool to examine students' learning of literacy skills and it is an effective way to support journal writing to students with low English language proficiency. As a research tool, Scaffold writing makes it possible to establish and shift student's language development from CPD to ZPD when the lower level is determined by the child's unassisted learning as seen in Zone of current development during week 1 and the teacher's assisted learning which then shifts to students' autonomous learning. The conclusion of this study supports that scaffolding technique would help students develop themselves and become autonomous learners. In sum, the scaffolding technique presented in this study has helped remedy the challenges faced by the target students by further developing the effectiveness in journal writing.

In order to get rid of the perception that poor writers will always remain poor, an educator can use Scaffolding that allows the teacher to help students transition from assisted tasks to independent performances. It is a step-by-step process that provides the learner with sufficient guidance until the process is learned, and then gradually removes the supports in order to transfer the responsibility for completing the task to the student. For scaffolding to be successful, the teacher must provide students with the optimal amount of support necessary to complete the task, and then progressively decrease the level of assistance until the student becomes capable of completing the activity independently.

\section{REFERENCES}

[1] Belland, B. R., Glazewski, K. D., \& Richardson, J. C. (2008). A scaffolding framework to support the construction of evidencebased arguments among middle school students. Educational Technology Research and Development, 56, 401-422.

[2] Christenson, T. A. (2002). Supporting struggling writers in the elementary classroom. Newark, DE: International Reading Association.

[3] Doolittle, P.E. (1997). Vygotsky's Zone of Proximal Development as a theoretical foundation for cooperative learning. Journal on Excellence in College Teaching, 8(1), 83-103.

[4] Herber, H.L., \& Herber, J.N. (1993). Teaching in content areas with reading, Writing and reasoning. Needham Heights, MA: Allyn \& Bacon.

[5] Lawson, L. (2002). Scaffolding as a teaching strategy. Paper presented in course EDUC 0500, Adolescent Learning and Development, City College of New York City (CUNY). Retrieved July 15, 2006, from condor.admin. ccny.cuny.edu/group4

[6] Mitchell, R \& Myles, F. (2004). Second language learning theories, London, UK: New York, USA, Arnold Publishers: Oxford University Press, 313pp.

[7] Palincsar, A.S., \& Brown, A.L. (1984). Reciprocal teaching of comprehension fostering and comprehension-monitoring activities. Cognitive Instruction, 1:117-75.

[8] Planas.G, Nelson L. (2008). A Systems Approach to Scaffold Communication Skills Development. American Journal of Pharmaceutical Education.

[9] Rasku-Puttonen, H, Etela pelto, A, Arvaja, M, \& Ha“kkinen, P. (2003). Is successful scaffolding an illusion? Shifting patterns of responsibility and control in teacher-student interaction during a long-term learning project. Instructional Science, 31:377-93.

[10] Scardamalia, M., \& Bereiter, C. (1985). Fostering the development of self-regulation in children's knowledge processing. In: Chipman SF, Segal JW, Glaser R, eds. Thinking and learning skills: Research and open questions. Hillsdale, NJ: Lawrence Erlbaum Associates.

[11] Tharpe, R. G. \& Gallimore, R. (1988). Rousing Minds to Life: Teaching, Learning, and Schooling in a Social Context. New York: Cambridge University Press.

[12] Vacca.(2008).Using scaffolding techniques to teach a social studies lesson about Buddha to sixth graders. Journal of adolescent \& adult Literacy $51: 8$.

[13] Vygotsky, L, S. (1978). Mind in society: The development of higher psychological processes. Cambridge, Mass; Harvard University Press.

[14] Vygotsky, L.S. (1978). Mind in society: The development of higher psychological processes (M. Cole, V. John-Steiner, S. Scribner, \& E. Souberman, Eds. \&Trans.). Cambridge, MA: Harvard University Press.

[15] Wood, D., Bruner, J., \& Ross, G. (1976). The role of tutoring in problem-solving. Journal of Child Psychology and Psychiatry, $17,89-100$.

[16] Walqui, A. (2002). Contextual factors in second language acquisition. Retrieved July 19, 2006, from www.cal.org/ resources/digest/0005contextual.html. 


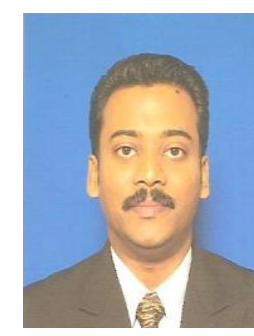

Veeramuthu A/L Veerappan was born in Johor Bahru, Malaysia on the $17^{\text {th }}$ February 1975 . He has completed his Diploma in Management from Institute of Tun Abdul Razak in 1998, has obtained a Bachelor of Education (TESL) 2006 and Master in Applied Linguistics (English) 2010 from University Putra Malaysia. His major field of study is in teaching English as a second language and applied linguistics.

He started teaching career in SMK (LKTP) Tengaroh A in the year 2000. He is currently working as lecturer at FOSEE, Malaysian Multimedia University. He has experience teaching English as Second Language for 11 years for both local and International students. His research area of interest is ESL writing and sociolinguistics.

Wei Hui Suan is currently a Japanese Language lecturer in Centre for Foundation Studies and Extension Education (FOSEE), Multimedia University. She obtained her Bachelor of Arts and Letters (Applied Linguistic) from Tohoku University, Japan in 2004 and pursued her Masters in University Putra Malaysia in the field of Educational Psychology and graduated in 2008. She is an experienced educator with a total of more than 16 years experience in language teaching in primary schools, secondary school and university. Her research areas of interest are in the field of teaching and learning and Educational Psychology, specifically Multiple Intelligences, thinking skills and cognitive development.

Tajularipin Sulaiman Ph.D is currently a lecturer in Faculty of Educational Studies, University Putra Malaysia. He received his early education in Muar, Johor and continued his secondary education at the Sekolah Teknik Malacca. He continued his studies at the Centre for Foundation Studies in Science, Universiti Malaya in 1998. He obtained a degree in Bachelor of Science with Education in 1994 and Master of Education in 1998 from University Malaya. He holds a doctoral degree in education from University Putra Malaysia. His area of specialization is in pedagogy, science education, and cognitive development. He has involved teaching and researching in science education, thinking skills and primary education. His research interest is in the field of pedagogy and primary education especially in primary science. He has also presented papers in national and international conferences 